\title{
KONSUMSI APEL MERAH MEMPENGARUHI PERUBAHAN TINGKAT DEMENSIA PADA LANSIA DI RT 05 RW 03 KELURAHAN WONOKROMO
}

\author{
Ernawati*, Lono Wijayanti** \\ UNUSA, FKK, Prodi SI Keperawatan - Jl. Smea 57 Surabaya \\ Email : Lonowijayanti@ymail.com
}

\begin{abstract}
ABSTRACK: Dementia to elder is abnormality which can be prevented by consuming red apple. Therefore, this research was purposed to find out the influence of red apple consumption to elder dementia level at Wonokromo $R T 05 \mathrm{RW} 03$. The research used quasi-experiment design, where the population involved 20 elders who got dementia symptom. All populations were taken as the sample using total sampling technique. 8 people were taken as experiment grup and 12 people as control group. The independent variable was red apple consumption whereas the dependent one was dementia level. Moreover, the data collected by using MMSE and analyzed using Fisher Exact Test with $\alpha=0,05$. The result of this research showed that there was difference of dementia level between before and after consuming red apple to experiment and control group. Furthermore, the Fisher Exact Test obtained the value of $\rho=0,018$ showing that $H_{0}$ was rejected, means there was influence of red apple consumption to elder changes of dementia level at Wonokromo RT $05 R W 03$. The research concluded that red apple could change the levelt of dementia. Hence, diagnosed as dementia should consume red apple regularly and health worker could give health education about the benefit of red apple to dementia.
\end{abstract}

ABSTRAK: Demensia (kepikunan) pada lansia bukanlah hal yang normal, dan bisa dihambat dengan mengkonsumsi apel merah. Tujuan penelitian ini untuk mengetahui pengaruh konsumsi apel merah terhadap perubahan tingkat demensia pada lansia di RT 05 RW 03 Kelurahan Wonokromo. Metode penelitian menggunakan Quasy Eksperimen, populasinya 20 lansia yang mengalami gejala demensia. Pengambilan sampel secara total sampling, didapat 8 orang kelompok eksperimen dan 12 orang kelompok kontrol. Variabel independen penelitian ini adalah konsumsi apel merah dan variabel dependen tingkat demensia. Pengumpulan data dilakukan menggunakan MMSE dan dianalisis menggunakan Uji Fisher Exact dengan $\alpha=0,05$. Hasil penelitian, ada perbedaan tingkat demensia antara sebelum dan sesudah konsumsi apel merah pada kelompok studi dan kelompok kontrol. Hasil uji Fisher Exact didapatkan $\rho=0,018$. Oleh karena $\rho<\alpha, \mathrm{H}_{0}$ ditolak, berarti ada pengaruh konsumsi apel merah terhadap perubahan tingkat demensia pada lansia di RT 05 RW 03 Kelurahan Wonokromo. Simpulan penelitian ini adalah apel merah dapat merubah tingkat demensia. Diharapkan pada penderita demensia tetap mengkonsumsi apel merah setiap hari, dan bagi pelayanan kesehatan dapat memberikan pendidikan kesehatan tentang manfaat apel merah untuk demensia.

Kata kunci : Tingkat Demensia, Konsumsi Apel Merah 


\section{PENDAHULUAN}

Saat ini apel merupakan salah satu buah populer dan relatif mudah ditemukan di Indonesia. Selain karena rasanya manis, apel mengandung banyak zat yang menyehatkan serta bermanfaat besar bagi tubuh (Rifai, 2013). Apel mengandung khasiat asupan makanan yang banyak dan juga memiliki khasiat obat yang dianjurkan oleh dokter semenjak zaman dahulu hingga masa kini (Dedimisbahatori, 2013). Salah satu khasiat apel sebagai obat adalah dapat membantu meningkatkan daya ingat otak dan mengurangi gejala dari demensia (Alzheimer's Australia, 2010). Demensia (kepikunan) sangat erat hubungannya dengan lansia. Mitos yang terdapat di masyarakat bila lanjut usia mengalami demensia atau kepikunan, hal itu merupakan proses menua sehingga sering dianggap sebagai hal yang wajar saja dan bila lanjut usia sudah menderita demensia sudah tidak bisa dilakukan apa-apa lagi. Pada Kenyataannya demensia stadium ringan dang sedang klien masih bisa ditolong bila terdeteksi secara dini, diberikan nasihat, dan bantuan informasi yang baik dan benar (Nugroho, 2008).

Data dari Encyclopedia Britannica menyebutkan bahwa pada tahun 2005 terdapat 24,3 juta orang mengalami pikun di seluruh dunia, sedangkan tahun 2010 jumlahnya meningkat 35,6 juta orang. Di Inggris, terdapat kurang lebih 18.000 penderita demensia dengan usia dibawah 65 tahun. Organisasi Kesehatan Dunia (WHO) memperingatkan bahwa penderita demensia di seluruh dunia akan naik dua kali lipat menjadi 65,7 milyar pada 2030. Marc Wortmann, direktur eksekutif dari 78 organisasi asosiasi Alzheimer mengatakan bahwa setiap 4 detik terdapat penderita baru demensia di dunia, dan bila diproyeksikan ke depan, mungkin akan ada satu 1 kasus baru setiap detik pada 2050 (Khatijah, 2013). World
Alzheimer's Report 2013 memprediksi bahwa jumlah orang lansia yang dependen akan meningkat dari 101 juta menjadi 277 juta dalam 2050. Hampir setengahnya hidup dengan penyakit Alzheimer atau jenis demensia lainnya yang secara cepat akan menjadi krisis global (ADI, 2013). Ahli psikiatri geriatri FKUI-RSCM, Dr. dr. Martina WS Nasrun SpKJ (K) menyatakan bahwa di Indonesia diperkirakan pada 2050 penderita demensia alzheimer bisa mencapai 3 juta kasus (Rosari, 2013). Berdasarkan survei awal yang dilakukan peneliti di RT 05 RW 03 Kelurahan Wonokromo, telah ditemukan beberapa data. Adapun data yang di peroleh, yaitu: kondisi daya ingat pada lansia yang bergabung di posyandu Rekso Werdo, tiga dari lima lansia mengatakan sering lupa hari dan tanggal, lupa pada kegiatan sehari-hari, seperti: lupa meletakkan kunci, lupa meletakkan pisau saat memasak, lupa meletakkan dompet, dan lupa meletakkan benda yang baru saja di bawa, padahal benda yang dimaksud dengan genggaman lansia. Keadaan tersebut menunjukkan bahwa telah terjadi gejala demensia pada lansia.

Otak sangat mudah rusak akibat radikal bebas, karena bahan kimia berbahaya ini mudah terserap oleh lemak sedangkan sebagian besar struktur otak adalah lemak sehingga para peneliti sepakat bahwa radikal bebas merupakan penyebab tanda-tanda penuaan (Paretta, 2005). Penuaan pada lansia menyebabkan terjadinya perubahan anatomi dan biokimiawi di susunan saraf pusat yaitu berat otak akan menurun sebanyak sekitar $10 \%$ pada penuaan antara umur 30 - 70 tahun. Pada proses penuaan otak, terjadi penurunan jumlah neuron secara bertahap yang meliputi area girus temporal superior (merupakan area yang paling cepat kehilangan neuron), girus presentralis dan area striata. Secara patologis penurunan jumlah neuron kolinergik akan 
menyebabkan berkurangnya neurotransmiter asetilklolin sehingga menimbulkan gangguan kognitif dan perilaku (Soetedjo, 2006). Prognosis untuk jenis demensia progresif dapat bervariasi mencakup deteriorasi progresif kemampuan fisik dan mental seseorang sampai meninggal. Pada tahap akhir, klien biasanya memiliki fungsi kognitif dan motorik minimal, secara total bergantung pada pemberian perawatan untuk perawatan harian, dan tidak menyadari lingkungan sekitarnya atau orang-orang di lingkungan tersebut. Klien tidak dapat berkomunikasi secara total dan membuat suara-suara atau berusaha mengungkapkkan hal-hal yang tidak dapat dimengerti (Videback, 2008).

Perkembangan Demensia dapat dicegah atau diperlambat dengan menggunakan obat Takrin (Cognex) suatu agonis kolinergik dan inhibitor kolinestrase seperti donezepil (Aricept) (Videback, 2008). Selain menggunakan obat, perkembangan demensia dapat dihambat dengan diit yang sehat (Mandal, 2013). Buah-buahan yang mengandung quercetin, vitamin $\mathrm{A}$, vitamin $\mathrm{C}$, karoten, asetilkolin, seperti apel merah dapat melindungi otak dari radikal bebas dan meningkatkan atau menambah daya ingat.

\section{METODE}

Pada penelitian ini desain penelitian yang digunakan adalah Quasy Eksperiment Design, yaitu rancangan yang berupaya untuk mengungkapkan hubungan sebab akibat dengan cara melibatkan kelompok kontrol disamping kelompok eksperimental. Dalam penelitian ini lansia yang mengalami kepikunan atau demensia akan diberikan apel merah pada kelompok eksperimental dan tidak diberikan apel merah pada kelompok kontrol. Pada kelompok lansia tersebut penelitian akan diawali dengan pretest, dan setelah pemberian perlakuan diadakan pengukuran kembali (posttest).

\begin{tabular}{clcc}
\hline Subjek & Pra & Perlakuan & Pasca-tes \\
\hline K-A & O & I & O1-A \\
\hline K-B & O & - & O-B \\
\hline & Time 1 & Time 2 & Time 3
\end{tabular}

Gambar:Desain Penelitian Pengaruh Konsumsi Apel Merah Terhadap Perubahan Tingkat Demensia

Sumber : Nursalam, 2013

Keterangan:

K-A : subyek perlakuan

K-B : subyek kontrol

- $\quad$ : tidak diberikan apel merah

$\mathrm{O} \quad$ : pengukuran tingkat

demensia.

I : intervensi ( pemberian apel

merah )

$\mathrm{O} 1(\mathrm{~A}+\mathrm{B}) \quad$ : pengukuran tingkat demensia sesudah diberikan apel merah

(kelompok kontrol dan kelompok eksperimental)

Populasi dalam penelitian ini adalah seluruh lansia berumur 60 tahun ke atas yang mengalami gejala demensia di RT 05 RW 03 Kelurahan Wonokromo pada tahun 2013 yaitu sebesar 20 orang.

Cara pengambilan sampel,Dua puluh sampel yang ada akan di randomisasi (random alocation) untuk menentukan siapa diantara sampel yang mendapatkan perlakuan atau tidak mendapat perlakuan dengan peluang yang sama. Pembagian subyek penelitian dilakukan dengan randomisasi sederhana, yaitu dengan menggunakan tabel angka random dengan ketentuan:

1. Kelompok kontrol (K): untuk angka 0 - 4

2. Kelompok eksperimen (E): untuk angka 5-9

Peneliti menutup mata dan memillih kolom pada tabel random menurut Kasjono (2009) dengan pensil, kemudian nomer kolom yang terpilih ( kolom 3) dibaca ke bawah sampai 20 baris, sehingga dihasilkan nomer random: 22 $755123432202995314=\mathrm{K} \mathrm{K}$ E E E K K K E K K K K K E E E K K E. 
Dari hasil random di atas didapatkan kelompok kontrol sebesar 12 orang dan kelompok eksperimen (studi) 8 orang.

Instrumen penelitian adalah suatu alat yang digunakan oleh peneliti untuk mengobservasi, mengukur atau menilai suatu fenomena. Dalam penelitian ini instrumen yang digunakan adalah dengan menggunakan lembar kuesioner MMSE (Mini Mental State Examination) dan lembar observasi yang dilakukan selama lima hari. Tes MMSE akan dilakukan sebelum dan sesudah diberikan perlakuan konsumsi apel merah. Tes MMSE berisi beberapa sub bab pertanyaan meliputi:

a. Orientasi: nilai maksimal 10 poin. Pertanyaan terdiri dari 2 soal, soal pertama berisi tentang waktu (5 poin) soal kedua tentang tempat (5 poin). Setiap soal memiliki 5 jawaban dengan nilai masing-masing 1 poin. Jawaban salah bernilai 0 .

b. Registrasi: nilai maksimal 3 poin. Peneliti meminta klien menyebutkan 3 benda (kereta, pensil, kertas atau bola, kereta, buku) yang telah disebutkan oleh peneliti. Setiap satu benda yang disebutkan dengan benar bernilai 1 poin, jawaban yang salah beri nilai 0 .

c. Perhatian dan Kalkulasi: nilai maksimal 5. Peneliti meminta lansia mengeja kata "dunia" dari belakang secara spontan, setiap abjad yang disebutkan dengan benar bernilai 1 poin, kesalahan menyebutkan 1 abjad bernilai 0 .

d. Ingatan : nilai maksimal 3. Peneliti meminta lansia menyebutkan kembali tiga benda yang disebutkan pada soal registrasi. Masing-masing benda yang disebutkan bernilai 1 poin.

e. Bahasa: nilai maksimal 9 poin dengan penjabaran:

1) Pertanyaan pertama bernilai 2 poin dengan meminta lansia menyebutkan pukul berapa sesuai dengan jam pada saat tersebut (1 poin), kemudian meminta lansia menyebutkan nama pensil (1 poin).

2) Pertanyaan kedua bernilai 1 poin, dengan meminta lansia menyebutkan kalimat yang berisi frasa tidak ada, apabila, dan atau tetapi".

3) Pertanyaan ketiga bernilai 3 poin. Meminta lansia mengikuti 3 perintah peneliti (Ambil kertas dengan tangan kanan anda kemudian lipat menjadi dua dan letakkan di meja). Setiap perintah yang dilakukan dengan benar bernilai 1 poin, perintah yang salah bernilai 0 .

4) Pertanyaan keempat bernilai 1 poin meminta lansia membaca perintah yang sudah dituliskan ("Tutup mata, anda!" atau "Angkat tangan kanan, Anda!) kemudian melakukan perintah tersebut.

5) Pertanyaan kelima bernilai 1 poin. Peneliti meminta lansia menuliskan satu kalimat dengan spontan. Apabila kalimat mengandug subjek dan kata kerja maka bernilai 1 poin.

6) Pertanyaan keenam benilai 1 poin. Peneliti meminta lansia untuk menirukan bentuk dua segilima yang sudah digambar oleh peneliti.

Setelah data terkumpul kemudian dilakukan pengelompokan data. Setelah data diolah secara manual, data di analisis menggunakan uji Fisher Exact

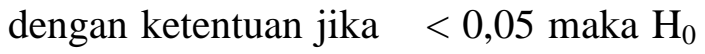
ditolak yang berarti ada pengaruh konsumsi apel merah terhadap perubahan tingkat demensia pada lansia.

\section{HASIL}

1. Data Umum Responden

Data umum berisi karakteristik yang meliputi umur, jenis kelamin, dan pendidikan.

a. Karakteristik responden berdasarkan umur 
Tabel 5.1 Distribusi frekuensi responden kelompok kontrol berdasarkan umur lansia RT 05 RW 03 Kelurahan Wonokromo

\begin{tabular}{ccc}
\hline $\begin{array}{c}\text { Umur } \\
\text { (tahun) }\end{array}$ & Jumlah & Persentase $(\%)$ \\
\hline $60-69$ & 7 & 58,3 \\
$70-79$ & 4 & 33,3 \\
$80-89$ & 1 & 8,3 \\
\hline Jumlah & 12 & 100 \\
\hline
\end{tabular}

Sumber: Data Primer Maret 2014

Pada tabel 5.1 menujukkan bahwa dari 12 responden kelompok kontrol sebagian besar $(58,3 \%)$ berumur $60-69$ tahun (Young old).

Tabel 5.2 Distribusi frekuensi responden kelompok studi berdasarkan umur lansia RT 05 RW 03 Kelurahan Wonokromo

\begin{tabular}{ccc}
\hline $\begin{array}{c}\text { Umur } \\
\text { (tahun) }\end{array}$ & Jumlah & Persentase (\%) \\
\hline $60-69$ & 5 & 62,5 \\
$70-79$ & 3 & 37,5 \\
$80-89$ & 0 & 0 \\
\hline Jumlah & 8 & 100 \\
\hline
\end{tabular}

Sumber: Data Primer Maret 2014

Pada tabel 5.2 menunjukkan bahwa dari 8 responden kelompok studi sebagian besar $(62,5 \%)$ berumur 60-69 tahun (Young old).

b. Karakteristik responden berdasarkan jenis kelamin

Tabel 5.3 Distribusi frekuensi responden berdasarkan jenis kelamin lansia di RT 05 RW 03 Kelurahan Wonokromo

\begin{tabular}{ccc}
\hline Jenis & \multicolumn{2}{c}{ Jumlah responden } \\
Kelamin & $\begin{array}{c}\text { Kelompok } \\
\text { kontrol } \\
(\%)\end{array}$ & $\begin{array}{c}\text { Kelompok } \\
\text { eksperimen }(\%)\end{array}$ \\
\hline Laki-laki & $3(25)$ & $3(37,5)$ \\
Perempuan & $9(75)$ & $5(62,5)$ \\
\hline Jumlah & $12(100)$ & $8(100)$
\end{tabular}

Sumber: Data Primer Maret 2014

Pada tabel 5.3 menunjukkan

bahwa sebagian besar kelompok responden dari kelompok studi $(62,5 \%)$ dan kelompok kontrol (75\%) adalah perempuan.

c. Karakteristik responden berdasarkan tingkat pendidikan

Tabel 5.4 Distribusi frekuensi responden berdasarkan tingkat pendidikan pada lansia di RT 05 RW 03 Kelurahan Wonokromo

\begin{tabular}{ccc}
\hline Tingkat & \multicolumn{2}{c}{ Jumlah responden } \\
\cline { 2 - 3 } Pendidikan & $\begin{array}{c}\text { Kelompok } \\
\text { kontrol }(\%)\end{array}$ & $\begin{array}{c}\text { Kelompok studi } \\
(\%)\end{array}$ \\
\hline Pendidikan Dasar & $6(50)$ & $5(62,5)$ \\
Pendidikan & $3(25)$ & $3(37,5)$ \\
Menengah & & $0(0)$ \\
Pendidikan & $3(25)$ & \\
Tinggi & & $8(100)$ \\
\hline Jumlah & $12(100)$ &
\end{tabular}

Sumber: Data Primer Maret 2014

Pada tabel 5.4 menunjukkan bahwa dari 12 responden kelompok studi sebagian besar (62,5\%) tingkat pendidikan dasar. Demikian halnya kelompok kontrol, setengah (50\%) dari 8 responden kelompok kontrol tingkat pendidikanya adalah pendidikan dasar.

\section{Data Khusus}

a. Tingkat demensia kelompok kontrol dan kelompok studi sebelum diberikan konsumsi apel merah

Tabel 5.5 Distribusi frekuensi tingkat demensia pada responden sebelum perlakuan konsumsi apel merah pada kelompok kontrol dan kelompok studi

\begin{tabular}{cccccc}
\hline Subyek & \multicolumn{3}{c}{ Tingkat Demensia } & & Tota \\
& Norm & Ringa & Sedan & Ber & 1 \\
& al $(\%)$ & $\mathrm{n}(\%)$ & $\mathrm{g}(\%)$ & at & \\
& & & & $(\%)$ & \\
\hline $\begin{array}{c}\text { Kelomp } \\
\text { ok studi }\end{array}$ & $0(0)$ & $6(75)$ & $2(25)$ & 0 & 8 \\
Kelomp & 4 & $6(50)$ & 2 & 0 & 12 \\
ok & $(33,3)$ & & $(16,7)$ & $(0)$ & $(100$ \\
kontrol & & & & & $(0)$ \\
\hline
\end{tabular}

Sumber: Data Primer Maret 2014

Pada tabel 5.5 menunjukkan bahwa dari 8 responden kelompok eksperimen sebagian besar $(75 \%)$ memiliki tingkat demensia ringan. Sedangkan dari 12 responden kelompok kontrol setengahnya $(50 \%)$ juga memiliki tingkat demensia ringan.

b. Tingkat demensia kelompok studi dan kelompok kontrol setelah 
diberikan perlakuan konsumsi apel merah

Tabel 5.6 Distribusi frekuensi tingkat demensia responden setelah perlakuan konsumsi apel merah pada kelompok kontrol dan kelompok studi

\begin{tabular}{ccccccc}
\hline Subyek & \multicolumn{4}{c}{ Tingkat Demensia } & \multicolumn{2}{c}{ Total } \\
\cline { 2 - 4 } & Normal & Ringan & Sedang & Berat & \\
\hline Kelompok & 3 & 5 & $0(0)$ & $0(0)$ & 8 \\
studi & $(37,5)$ & $(62,5)$ & & & $(100)$ \\
Kelompok & $3(25)$ & $6(50)$ & $3(25)$ & $0(0)$ & 12 \\
kontrol & & & & & $(100)$ \\
\hline
\end{tabular}

Sumber: Data Primer Maret 2014

Pada tabel 5.6 menunjukkan bahwa dari dari 8 responden kelompok studi setelah diberikan perlakuan konsumsi apel merah sebagian besar $(62,5 \%)$ memiliki tingkat demensia ringan. Pada kelompok kontrol setengahnya (50\%) memiliki tingkat demensia ringan.

c. Perbedaan perubahan tingkat demensia antara yang diberi konsumsi apel merah dan yang tidak diberi konsumsi apel merah

Tabel 5.7 Tabulasi silang pengaruh konsumsi apel merah terhadap perubahan tingkat demensia pada lansia di RT 05 RW 03 Keliurahan Wonokromo

\begin{tabular}{|c|c|c|c|}
\hline \multirow{2}{*}{$\begin{array}{c}\text { Perlakuan } \\
\text { Konsumsi } \\
\text { Apel } \\
\text { Merah }\end{array}$} & \multicolumn{3}{|c|}{ Perubahan Tingkat Demensia } \\
\hline & $\begin{array}{c}\text { Ada } \\
\text { Perubah } \\
\text { an }\end{array}$ & $\begin{array}{l}\text { Tidak Ada } \\
\text { Perubahan }\end{array}$ & Total \\
\hline Diberikan & $\begin{array}{c}5 \\
(62,5 \%)\end{array}$ & $3(37,5 \%)$ & $8(100 \%)$ \\
\hline Tidak & 1( & $11(91,7)$ & $12(100 \%)$ \\
\hline Diberikan & $8,3 \%)$ & & \\
\hline Total & $6(30 \%)$ & $14(70 \%)$ & $20(100 \%)$ \\
\hline
\end{tabular}

Sumber: Data Primer Maret 2014

Pada tabel 5.7 menunjukkan bahwa dari 20 responden, 6 orang (30\%) mengalami perubahan tingkat demensia dan 14 orang (70\%) tidak mengalami perubahan tingkat demensia. Hasil analisis menggunakan uji Fisher Exact didapatkan nilai probabilitas $=0,018$.
Oleh karena $\rho<\alpha(0,018<0,05)$ maka $\mathrm{H}_{0}$ Ditolak yang berarti ada pengaruh konsumsi apel merah terhadap perubahan tingkat demensia pada lansia di RT 05 RW 03 Kelurahan Wonokromo. Lalu didapatkan nilai $\mathrm{OR}=18,3$ dengaan $\mathrm{CI}$ 95\%: 1,508 - 222,875. Artinya pada kelompok yang diberikan konsumsi apel merah akan terjadi perubahan tingkat demensia 18,3 kali daripada yang tidak diberikan konsumsi apel merah

\section{PEMBAHASAN}

Hasil dari penelitian pada tabel 5.5 menunjukkan bahwa tingkat demensia pada kelompok studi sebelum diberikan konsumsi apel merah sebagian besar $(75 \%)$ memiliki tingkat demensia ringan dan tingkat demensia pada kelompok kontrol setengahnya (50\%) juga memiliki tingkat demensia ringan. Dari hasil penelitian diatas dapat disimpulkan bahwa terdapat persamaan rata-rata tingkat demensia sebelum diberikan konsumsi apel merah pada kelompok kontrol dan kelompok eksperimen yaitu tingkat demensia ringan. Hal ini disebabkan karena lansia menganggap bahwa kepikunan adalah hal biasa dan bukan masalah kesehatan yang harus diperhatikan. Mitos yang terdapat di masyarakat bila lanjut usia mengalami demensia atau kepikunan, hal itu merupakan proses menua sehingga sering dianggap sebagai hal yang wajar saja dan bila lanjut usia sudah menderita demensia alzeimer sudah tidak dapat dilakukan apa-apa lagi (Nugrooho, 2008).

Demensia stadium ringan dan sedang, pada kenyataannya klien masih dapat ditolong bila terdeteksi secara dini, diberikan nasihat, dan bantuan informasi yang baik dan benar. Daya ingat yang buruk merupakan abnormalitas dan perlu diperiksakan ke dokter ahli. Demensia atau kepikunan bukanlah hal yang alamiah, tetapi merupakan kondisi sakit yang disebabkan oleh kematian atau 
kerusakan sel otak (Nugroho, 2008). Proses klinis demensia digambarkan dalam tahap demensia ringan, demensia sedang, dan demensia berat. Pelupa merupakan tanda awal demensia ringan, pelupa dalam hal ini melebihi pelupa yang kadang-kadang terjadi dan normal yang dialami sebagai bagian proses penuaan. Pada demensia sedang, kebingungan muncul bersamaan dengan kehilangan memori yang progresif, individu tidak dapat lagi melakukan tugas yang kompleks tetapi tetap terorientasi terterhadap orang dan tempat. Sedangkan pada demensia berat sudah terjadi perubahan kepribadian dan emosional seperti waham, berkeluyuran di malam hari, dan melupakan keluarganya (Videbeck, 2009). Penentuan tingkat demensia dapat dilakukan dengan menggunakan tes MMSE (Mini Mental State Examination) ( Azizah, 2011). Memori merupakan salah satu fungsi kognitif yang terdistribusi pada setiap otak individu. Selain memori, atensi dan konsentrasi, fungsi eksekutif, fungsi yang terlokalisasi (hemisfer dominan dan hemisfer nondominan) juga dapat terganggu pada penderita demensia (Ginsberg, 2008).

Selain itu usia juga mempengaruhi tingkat demensia pada lansia. Pada tabel 5.1 hasil menunjukkan dari 12 responden kelompok kontrol sebagian besar $(58,3 \%)$ berumur 60-69 tahun (Young Old). Demikian juga dengan kelompok eksperimen, dimana sebagian besar (62,5\%) dari 8 responden berumur 60-69 tahun. Pada lanjut usia akan sering muncul keluhan semakin pelupa. Kondisi semakin menjadi pelupa ini selain akibat proses penuaan sel-sel otak, juga dapat disebabkan karena berkurangnya pasokan gizi melalui makanan untuk otak.

Hal ini juga sesuai dengan teori Nugroho (2008) yang menyebutkan bahwa usia adalah faktor risiko utama untuk demensia. Demensia dapat terjadi pada siapa saja, tetapi lebih umum setelah orang berumur 65 tahun. Orang usia 40-an dan 50-an juga dapat terkena demensia (Alzheimer's Australia, 2005). Problem yang dihadapi orang berusia lanjut adalah berkurangnya bobot otak, dimana pada manusia dengan usia memasuki 50 tahun maka terjadi penyusutan otak dengan berat otak berkurang menjadi 1.2 kilogram dan $20 \%$ dari kurang lebih 100 miliar sel otak terdegenerasi (Setiabudi, 2012).

Pada tabel 5.6 menunjukkan bahwa dari 8 responden kelompok studi sebagian besar $(62,5 \%)$ responden memiliki tingkat demensia sedang. Penurunan tingkat demensia terjadi setelah responden mengkonsumsi apel merah selama lima hari berturut-turut. Setiap responden pada kelompok eksperimen harus menghabiskan satu buah apel merah dalam satu hari. Responden diminta untuk mengkonsumsi satu buah apel merah utuh beserta kulitnya, dan peneliti menjelaskan tujuan dari penelitian. Apel merah didistribusikan ke rumah responden dimulai setiap pukul 06.30 WIB. Peneliti akan menemani responden yang tinggal sendiri untuk memastikan bahwa responden menghabiskan apelnya. Akan tetapi apabila responden menolak untuk ditemani dikarenakan alasan tertentu maka peneliti akan bekerjasama dengan angota keluarga responden untuk menjadi observer menggantikan peneliti.

Penurunan jumlah persentase responden dengan tingkat demensia sedang dan peningkatan tingkat demensia dalam batas ambang (normal) pada kelompok studi membuktikan bahwa mengkonsumsi satu buah apel utuh dan segar yang dikonsumsi secara rutin dapat melawan proses penuaan pada otak dan dapat menghambat proses perkembangan demensia. Apel dapat meningkatkan daya ingat responden, hal ini terbukti dengan peningkatan persentase tes ingatan pada tes MMSE. 
Apel merah (red delicious) adalah salah satu jenis apel yang berasal dari Amerika berbentuk hati cerah merah dan kadang-kadang bergaris. Rasa apel merah ini agak manis dan renyah (Gravity, 2014). Buah Apel baik bagi kesehatan saraf, buahnya mengandung antioksidan yang disebut dengan quercetin yang mencegah kerusakan sel yang disebabkan oleh oksidasi dan peradangan neuron (jenis tertentu dari sel yang khusus untuk menyimpan dan mengirimkan informasi), mencegah penurunan mental progresif pada demensia, membantu melindungi sel-sel neuron terhadap stres oksidatif yang disebabkan oleh neurotoksisitas, mengurangi risiko penyakit Alzheimer, mengurangi risiko stroke, dll. Apel layak disebut "The First Power Food" karena mengandung nutrisi penting seperti vitamin $\mathrm{C}$ yang mampu mencegah kerusakan yang disebabkan oleh radikal bebas serta meningkatkan stamina tubuh, vitamin B-kompleks yang merupakan kunci dalam mempertahankan sel-sel darah merah dan sistem saraf agar dalam kondisi yang baik, dan fitonutrien yang membantu melindungi tubuh dari radikal bebas yang bersifat merusak, dan beberapa mineral seperti kalium, kalsium, dan fosfor (Agustinus, 2014). Apel utuh segar adalah bentuk yag terbaik untuk mendapatkan quercetin yang banyak ditemukan pada kulit apel. Apel merah umumnya memiliki lebih banyak antioksidan dibanding apel hijau (Pangkalan Ide, 2008). Selain kandungan yang disebutkan di atas, Astawan (2008) menambahkan bahwa apel juga mengandung karoten yang memiliki aktivitas sebagai vitamin A dan juga antioksidan yang berguna menangkal radikal bebas penyebab berbagai penyakit degeneratif.

Sedangkan pada kelompok kontrol pada tabel 5.6 menunjukkan setengahnya $(50 \%)$ memiliki tingkat demensia ringan, sebagian kecil (25\%) memiliki tingkat demensia ringan, dan sebagian kecil
(25\%) memiliki tingkat demensia sedang. Hasil penelitian pada kelompok kontrol ini dapat disimpulkan tidak ada perubahan ke arah positif (normal) dari keseluruhan responden. Peningkatan jumlah persentase pada tingkat demensia responden ini dapat dikarenakan karena reponden tidak memperhatikan faktorfaktor yang mempengaruhi tingkat demensia. Tidak adanya tindakan pencegahan demensia pada responden dapat memperparah tingkat demensia.

Mandal (2013) menyebutkan ada beberapa faktor yang dapat mencegah perkembangan demensia yaitu, diit yang sehat, berhenti merokok, mencegah penggunaan alkohol yang berlebihan, menjaga berat badan yang normal, melakukan olahraga secara teratur, kontrol tekanan darah dan diabetes secara teratur, dan melakukan pencegahan lain seperti aktivitas otak dengan membaca, menulis catatan, harian, bermain teka-teki silang, dll. Sejauh ini, Pretta (2005) mengatakan bahwa para peneliti meyakini bahwa masalah memori umumnya dipahami sebagai kurang pasokan gizi melalui makanan, dan peneliti juga sepakat bahwa penyebab munculnya tanda-tanda penuaan adalah zat radikal bebas. Radikal bebas sendiri dapat disebabkan oleh makanan gorengan, radiasi, populasi, dan tubuh ketika mengatasi infeksi.

Tingkat pendidikan juga sangat berpengaruh terhadap kejadian maupun tingkat Demensia. Sesuai hasil penelitian, pada tabel 5.4 setengah $(50 \%)$ dari 12 kelompok kontrol memiliki tingkat pendidikan dasar dan dari 8 kelompok eksperimen sebagian besar $(62,5 \%)$ juga memiliki tingkat pendidikan dasar. Pendidikan yang rendah akan menjadikan seseorang tidak menggunakan otak untuk berpikir secara rutin, dan otak tidak terlatih sehingga daya ingat tidak dapat dijaga. Sedangkan kemunduran kognitif dapat diperlambat dengan melatih otak dan menggunakan otak secara rutin untuk 
berpikir. Dalam penelitian Fransisco et.al (2006), Metalitik Study didapatkan bahwa tingkat pendidikan seseorang merupakan faktor risiko terjadinya demensia terutama penyakit alzheimer. Added (2007) menyatakan bahwa seseorang yang memiliki tingkat pendidikan yang tinggi memiliki faktor pelindung dari risiko terkena demensia, tetapi hanya untuk menunda onset manifestasi klinis. Sehingga secara tidak langsung bedasarkan teori Added, seseorang yang tingkat pendidikannya rendah memiliki risiko lebih tinggi terkena demensia daripada orang yang berpendidikan tinggi.

Berdasarkan hasil analisis menggunakan uji Fisher Exact didapatakan nilai probabilitas 0,018. Nilai $\rho<\alpha$, sehingga $\mathrm{H}_{0}$ ditolak yang berarti ada pengaruh konsumsi apel merah terhadap perubahan tingkat demensia pada lansia di RT 05 RW 03 Kelurahan Wonokromo. Pengaruh dari satu buah apel yang dikonsumsi secara rutin ini membuktikan bahwa perkembangan demensia dapat di hambat dan salah satu caranya adalah dari makanan yang dikonsumsi setiap hari. Apel yang kaya aka kandungan antioksidannya dapat melindungi sel-sel otak dan meningkatkan daya ingat responden.

Pada hasil menunjukkan bahwa dari 8 responden kelompok studi 5 orang $(62,5 \%)$ mengalami perubahan tingkat demensia (penurunan tingkat demensia) dan 3 orang $(37,5 \%)$ tidak mengalami perubahan. Sedangkan pada kelompok kontrol didapatkan bahwa dari 12 responden 1 orang $(8,3 \%)$ mengalami perubahan tingkat demensia (tingkat demensia menurun) dan 11 orang $(91,7 \%)$ tidak mengalami perubahan (tingkat demensia tetap atau tingkat demensia meningkat) pada saat posttest. Satu orang yang mengalami penurunan tingkat demensia adalah orang yang memiliki tingkat demensia ringan pada saat pretest menjadi demensia dalam batas ambang pada saat posttest. Dari 11 orang yang tidak mengalami perubahan adalah 2 orang tetap pada tingkat demensia dalam batas ambang, 4 orang tetap dengan tingkat demensia ringan, 2 orang tetap dengan tingkat demensia sedang, 2 orang yang memiliki tingkat demensia dalam batas ambang pada saat pretest, tingkat demensia meningkat menjadi demensia ringan dan 1 orang dengan demensia ringan saat pretest menjadi demensia sedang pada saat posttest. Penurunan tingkat demensia pada satu responden kelompok kontrol dapat disebabkan karena responden memiliki pola makan yang sehat dan menambah aktivitas rutin seperti membaca, menulis, dll. Sedangkan 11 responden yang tidak mengalami perubahan tingkat demensia ke arah positif dapat disebabkan karena responden tidak begitu mempermasalahkan tentang dimensia atau kepikunan.

Seluruh responden yang mengkonsumsi apel merah selama lima hari secara rutin menghasilkan perubahan nilai tes MMSE ke arah yang positif (mendekati / menjadi normal). Perubahan pada kelompok studi dapat diuraikan sebagai berikut: dari 6 orang yang memiliki tingkat demensia ringan pada saat pretest, saat posttest 3 orang tetap pada tingkat demensia ringan dan 3 orang menjadi demensia dalam batas ambang. Dua orang yang memiliki demensia sedang pada pretest, tingkat demensia turun menjadi demensia ringan. Hasil penelitian ini menunjukkan bahwa perkembangan demensia benar-benar bisa dihambat dengan diit yang sehat. Berdasarkan hasil diatas dapat diyakini kebenaran khasiat apel yang disampaikan oleh Imam Shadiq r.a yang dikutip oleh Dedimisbahatori (2013) menyatakan bahwa "sekiranya orang-orang tahu khasiat apa yang terkandung dalam buah apel, maka mereka akan mengobati 
penyakit-penyakit mereka hanya dengan buah apel”.

Jenifer Wanner (2006) menyatakan bahwa satu atau dua buah apel dalam sehari dapat mencegah Alzheimer dan melawan proses penuaan pada otak dan kehilangan ingatan. Antioksidan dalam apel dapat membantu meningkatkan memori dan melawan penyakit alzheimer (Pangkalan Ide, 2008). Hal ini juga diperkuat dengan pernyataan peneliti Thomas Shea, $\mathrm{PhD}$, direktur pada Center for cellular Neurobiology \& Neurodegeneration Research di University of Massachusetts Lowell bahwa mengkonsumsi makanan kaya antioksidan seperti apel dan jus apel dapat membantu mengurangi masalah berkurangnya daya ingat (Pangkalan Ide, 2008).

Sebuah studi telah menunjukkan bahwa minum jus apel dapat meningkatkan memori dengan mencegah penurunan neurotransmiter penting yang disebut asetilkolin. Neurotransmiter merupakan bahan kimia yang dilepaskan sel saraf untuk menyampaikan pesan kepada sel saraf lain. Neurotransmiter sangat dibutuhkan untuk memori yang baik serta kesehatan otak. Studi sebelumnya menunjukkan bahwa peningkatan jumlah asetilkolin di otak dapat memperlambat penurunan mental pada pengidap penyakit alzheimer (Pangkalan Ide, 2008). Asetilkolin merupakan gabungan senyawa kimia yang berperan pada proses penyimpanan dan pemangilan kembali memori, perhatian (atensi), maupun tindak balas seseorang. Semakin banyak asetilkolin yang disintesis, semakin banyak pula yang dilepaskan ke dalam sistem saraf sehingga semakin baik pula proses memori proses memori dan atensi (hdindonesia.com).

\section{SIMPULAN}

1. Sebelum diberi konsumsi apel merah, tingkat demensia pada lansia di RT 05 RW 03 Kelurahan Wonokromo pada kelompok studi sebagian besar $(75 \%)$ memiliki tingkat demensia ringan, dan kelompok kontrol setengahnya $(50 \%)$ juga memiliki tingkat demensia ringan..

2. Setelah diberi konsumsi apel merah, tingkat demensia pada lansia di RT 05 RW 03 Kelurahan Wonokromo pada kelompok studi sebagian besar $(62,5 \%)$ memiliki tingkat demensia ringan dan pada kelompok kontrol setengahnya $(50 \%)$ memiliki tingkat demensia ringan.

3. Ada pengaruh konsumsi apel merah terhadap perubahan tingkat demensia pada lansia yang mengkonsumsi apel merah di RT 05 RW 03 Kelurahan Wonokromo.

\section{DAFTAR PUSTAKA}

Added, Ngadua. (2007). Low Education Level Independently Increase Dementia Risk www.medscape.com/viwarticle/563 595. Di akses pada tangal 10 April 2014, 08.21 WIB.

Agustinus. (2014). Manfaat Buah Apel. www.lifqual.com. Di akses pada tanggal 18 April 2014, 10.05 WIB.

Agoes, A.A., Agoes, Achdiat., Agoes, Arizal. (2010). Penyakit di Usia Tua. Jakarta, EGC.

Alzheimer's Australia. (2005). Apa itu Demensia?.

www.alzheimers.org.au. Di akses pada tanggal 18 Desember 2013, 06.45 WIB.

Alzheimer's Australia. (2010). Dementia News. www.fightdemensia.org.au. Diakses pada tanggal 17 Januari 2014m 16.25 WIB.

Alzheimer's Disease International (ADI). (2013). Laporan Alzheimer Dunia Tahun 2013 Menyatakan Epidemis Alzheimer Sedunia Menyebabkan Keterbatasan Jumlah Para Perawat dan Kekurangan Dukungan Bagi 
Anggota Keluarga. www.alzheimerindonesia.org. Di akses pada tanggal26 Februari 2014.

Ananda, Kun Sila. (2012). Tujuh Manfaat Mengejutkan dari Buah Apel. www.merdeka.com. Di akses pada tanggal 18 Desember 2013, 06:55 WIB.

Anderson, Linsday. (2013). Reserachers Have Made Assoiciations Between Apple Juice Consumption and Dementia. www.caringheartshomecareassita nce.com. Di akses pada tanggal 17 Januari 2014, 16.41 WIB/

Anna, Lusia Kus. (2011). Wajarkah Penderita Demensia Menjadi Pelupa. www.kompas.com. Di akses pada tanggal 23 November 2013, 15.04 WIB.

Astawan, Made. (2008). Sari Kesehatan Keluarga. Jakarta, Dian Rakyat.

Astawan, Made. (2009). A-Z Ensiklopedia Gizi Pangan untuk Keluarga. Jakarta, Dian Rakyat Nugroho.

Azizah, Lilik M. (2011). Keperawatan Lanjut Usia. Yogyakarta, Graha Ilmu.

Dedimisbahatori. (2013). Khasiat dan Manfaat Buah Apel. klinikpengobatanalami.wordpress. com. Di akses pada tanggal 18 Desember 2013, 14.18 WIB.

Dian, S. 2012. Pengaruh Jenis Kelamin, Pendidikan, dan Status Perkawinan Terhadap Kejadian Demensia Pada Lansia. www.publikasi.umy.ac.id. Di akses pada tanggal 17 April 2014, 14.09 WIB.

Fransisco, C., Montserrat, C., Agustin, M.M., dkk. (2006). Education and Dementia: A Meta-Analytic Studi (Abstract).Neuroepidemiology.
Diakses pada tanggal 20 April 2014, 09.12 WIB.

Ginsberg, Lionel. (2008). Lecture Notes: Neurologi, Edisi kedelapan. Jakarta, Penerbit Erlangga.

Godam. (2007). Faktor yang Mempengaruhi Tingkat Konsumsi / Pengeluaran Rumah Tangga Pendidikan Ekonomi Dasar. www.organisasi.org. Di akses pada tanggal 07 Januari 2014, 14.04 WIB.

Grayson, C. (2004). All about Alzheimer. Retrieved on October 2006 from http://www.webmd.com/content/a rticle/71/81413.htm.

Gravity. (2012). Jenis Apel. www.100buah.wordpress.com. Di akses pada tanggal 18 April 2014, 09.55 WIB.

Gunawan S, Tatang. (2013). Manfaat Buah Apel Untuk Kesehatan. www.aura-ilmu.com. Di akses pada tanggal 27 Desember 2013, 13.05 WIB.

Hastomo. (2013). Kandungan Gizi dan Manfaat Apel Bagi Kesehatan. Di akses pada tanggal 27 Desember 2013, 13.57 WIB.

KBBI._. Kamus Besar Bahsa Indonesiaonline. www.kbbi.web.id. Di akses pada tanggal 07 Januari 2013, 14.17 WIB.

Khatijah, Siti. (2013). Jumlah Semakin Meningkat.

www.m.suaramerdeka.com. Di akses pada tanggal 26 Pebruari 2014.

Khoirina, Aninya D. (2011). Faktorfaktor yang mempengaruhi Tingkat Konsumsi.

Anindyaditakhoirina.worpress.co m. Di akses pada tanggal 07 Januari 2014, 14.00 WIB

Kushariyadi. (2010). Asuhan Keperawatan pada Klien Lanjut Usia. Jakarta, Salemba Medika.

Mandal, Ananya. (2013). Dementia Prevention. Www.news- 
medical.net. Diakses pada tanggal 17 Januari 2014, 16.35 WIB.

Nugroho, Wahjudi. (2008). Keperawatan Gerontik \& Geriatrik, Edisi 3. Jakarta, ECG

Nugroho, Wahjudi. (2009). Komunikasi dalam Keperawatan Gerontik. Jakarta, EGC.

Nursalam. (2013). Metodologi Penelitian Ilmu Keperawatan Pendekatan Praktis, Edisi 3. Jakarta, Salemba Medika.

Pangkalan Ide. (2008). Tune up: Gaya Hidup Penghambat Alzheimer. Jakarta, Elex media Komputindo.

Pamgkalan Ide. (2013). Agar Otak Sehat 2. Jakarta, Elex Media Komputindo.

Perretta, Lorraine. (2005). Makanan Untuk Otak Panduan Penting untuk Meningkatkan Kemampuan Otak Anda. Jakarta: Penerbit Erlangga.

Paddock, Catherine., (2008). An Apple a Day Keeps Dementia Away. www.medicalnewstoday.com. Di akses pada tanggal 10 Januari 2014, 14.12 WIB.

Rifai. (2012). Manfaat dan Kandungan "Si Buah Merah" Apel. www.padatinfo.com. Diakses pada tanggal 18 Desember 2013, 08.15 WIB.

Rosari, Maria. (2013). Satu Juta Penduduk Indonesia Penderita Alzheimer. www.antaranews,com. Di akses pada tanggal 26 Februari 2014.

Sadock, Benjamin J., Sadock, Virginia A. (2010). Buku Ajar Psikiatri Klinis, Edisi 2Pustakamedia.com. Jakarta, EGC.

Santoso, Singgih. (2008). Panduan Lengkap Menguasai SPSS 16. Jakarta, Elex Media Komputindo.

Santrock, John W. (2012). Life - Span Development Perkembangan Masa Hidup, Edisi Ketigabelas, Jilid 2. Jakarta, Erlangga.
Setiabudi, Ananda. (2012). Kepikunan Pertanda Melemahnya Fungsi Saraf Memori. www.rsmeilia.co.id. Di akses apda tanggal 18 April 2014, 10.15 WIB.

Setiyani, Ristin. (2013). Manfaat Buah Apel. www.aura-ilmu.com. Diakses pada tanggal 18 Desember 2013, 06.45 WIB.

Smith, Melinda., Wayne, Melisa., Segal, Jeanne. (2013). Alzheimer's \& Dementia Prevention. Di akses pada tanggal 18 Januari 2014, 06.15 WIB.

Soetedjo. (2006). Diagnosis Gangguan Kognitif dan MCI Pada Usia Lanjut, dalam: Hexanto, M., \& Trianggoro, B., Update Management of Neurological Disorders in lderly, Pertemuan Ilmia Tahunan UNDIP-UGMUNS XXI.

Soraya, Ika. (2007). Tinjauan Pustaka (PDF). www.lontar.ui.ac.id. Diakses pada tanggal 08 Januari 2014, 06:34 WIB.

Sorensen, Susanne. (2010). Study Claims Apple Juice Could Help Reduce Agitation and Anxiety in People with Dementia. www.alzheimers.org.uk. Di akses pada tanggal 18 Januari 2014, 06.15 WIB.

Stanley, Mickey. (2006). Buku Ajar Keperawatan Gerontik, Edisi 2. Jakarta, EGC.

Sugiyono. (2011). Statistika untuk Penelitian. Bandung, Alfabeta.

Sunpride. (2010). Sepuluh Manfaat Kesehatan Apel Malang. www.sunpride.co.id. Di akses pada tanggal 18 Desember 2013, 05.53 WIB.

Videback, Sheila L. (2008). Buku Ajar Keperawatan Jiwa. Jakarta, EGC

Wanner, Jennifer. (2006). An Apple a Day for AD?. 
www.WebMD.Com. Di akses pada tanggal 17 Januari 2014, $16.38 \mathrm{WIB}$.

Wikipedia. (2013). Konsumsi. www.id.wikipedia.org. Di akses pada tanggal 07 Januari 2013, 14.19 WIB 